\title{
Comparison the Effects of Massage with Olive Oil and Sweet Almonds Oil on Prevention of Pressure Ulcer in Hospitalized Patients in ICU
}

\author{
Shokoh Varaei ${ }^{1}$, Leila Shirbeigi ${ }^{2}$, Leila Farahani ${ }^{3}$, Zeyinab Eslami Hassanabadi ${ }^{4}$, \\ Morteza Shamsizadeh*5
}

1. Associate Professor, School of Nursing and Midwifery, Tehran University of Medical Sciences, Tehran, Iran

2. Assistant Professor of Traditional Medicine, School of Persian Medicine, Department of Persian Medicine, Tehran University of Medical Sciences, Tehran, Iran

3. Department of Medical Surgical Nursing, School of Nursing and Midwifery, Tehran University of Medical Sciences, Tehran, Iran

4. Student Research Committee, School of Nursing and Midwifery, Tehran University of Medical Sciences, Tehran, Iran

5. Department of Medical Surgical Nursing, School of Nursing and Midwifery, Hamadan University of Medical Sciences, Hamadan, Iran

Article Info ABSTRACT

Received: 2018/03/09;

Accepted: 2019/03/14;

Published Online: 2019/08/28

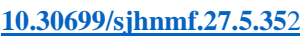

Original Article

Use your device to scan and read the article online

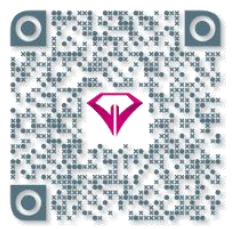

Corresponding Information:
Introduction: Pressure ulcer is a complication from which many patients suffer. Preventing this matter is one of the duties of nurses. The purpose of this study was to determine the effect of massage of olive oil with sweet almonds on prevention of pressure ulcer in patients hospitalized in ICU.

Methods: This study is a double-blind randomized clinical trial that was performed on 90 patients admitted to ICU Hospital in Maybod city, Yazd, Iran. Patients were selected by purposeful sampling and random blocked method in enrolled in two groups of test and one control group. The patients of the test groups received a massage in the areas exposed to risk of pressure ulcer for a week once a day with 3-1 $\mathrm{mL}$ of olive oil or sweet almonds. Also these two groups received the usual skin care including a change in position every two hours and a wavy mattress and control group received just the usual care of the skin. Data was collected using a demographic questionnaire and a checklist for potential areas with the risk of pressure ulcer using Braden's scale. Data was analyzed by Chi-square test, Fisher's exact test and variance analysis test in SPSS 16.

Results: There was no statistically significant difference between the groups in terms of demographic variables. The results showed that the incidence of pressure ulcers in the experimental groups was lower than the control group and in the olive oil massage group was lower than the sweet almond oil massage group $(P<0.05)$.

Conclusion: The results showed that olive Oil and sweet almond massage is effective in preventing pressure ulcer. A similar study to this study should be done using other herbal products such as Aloe Vera gel to prevent Pressure ulcer.

Keywords: Olive Oil, Sweet almonds oil, Prevention, Pressure ulcer, Massage

Morteza Shamsizadeh, Department of Medical Surgical Nursing, School of Nursing and Midwifery, Hamadan University of Medical Sciences, Hamadan, Iran. Email: mortezashamsizadeh@gmail.com

Copyright (C) 2019, This is an original open-access article distributed under the terms of the Creative Commons Attribution-noncommercial 4.0 International License which permits copy and redistribution of the material just in noncommercial usages with proper citation.

\section{How to Cite This Article:}

Varaei S, Shirbeygi L, Farahani L, Eslami Hasan Abadi Z, Shamsizadeh M. Comparison the Effects of Massage with Olive Oil and Sweet Almonds Oil on Prevention of Pressure Ulcer in Hospitalized Patients in ICU. Avicenna J Nurs Midwifery care. 2019; 27 (5) :352-360 


\section{مقايسة تأثير ماساز با روغن زيتون و روغن بادام شيرين در يِيشَيرى از زخم فشارى در بيماران بسترى در بخش آىسىيو: يك مطالعة كار آزمايى بالينى

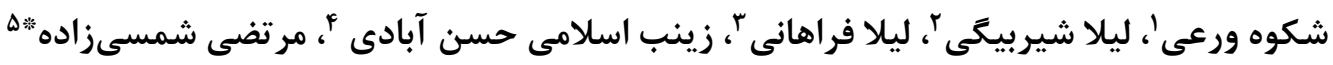

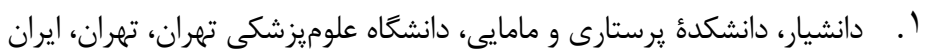

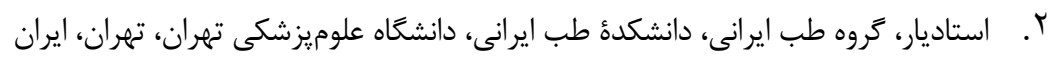

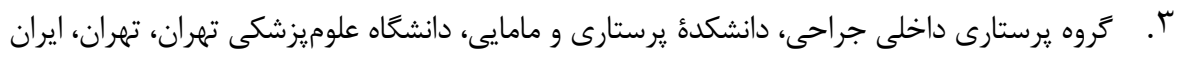

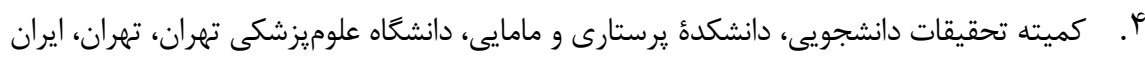

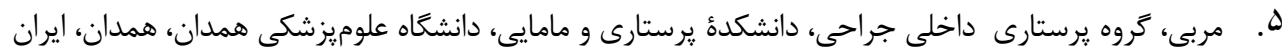

\begin{tabular}{|c|c|}
\hline جكيده & اطلاعات مقاله \\
\hline 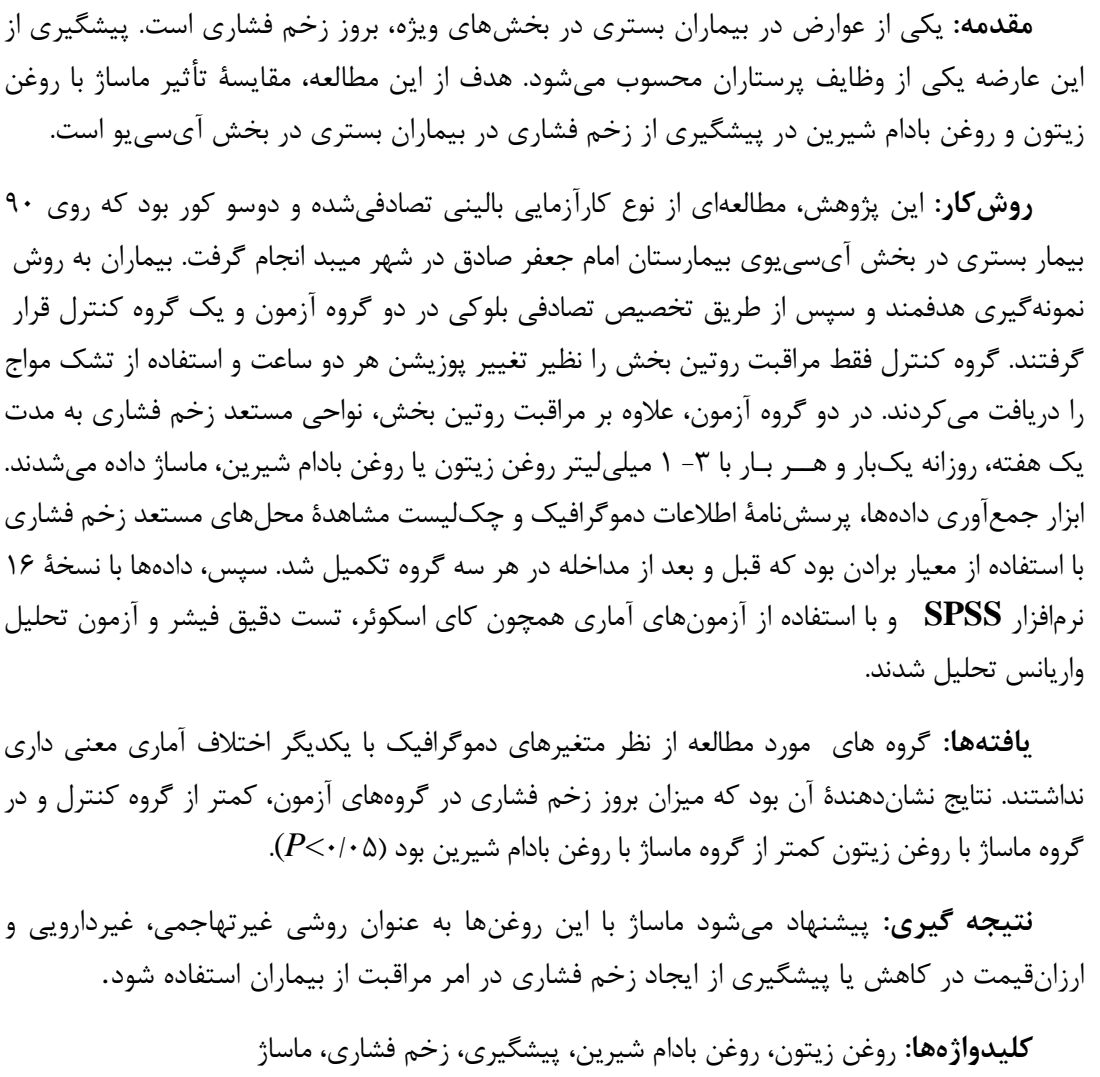 & 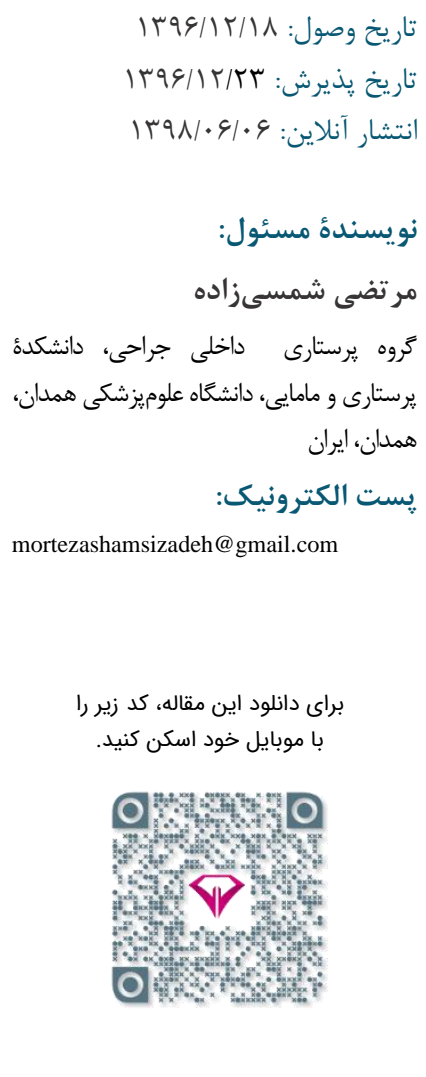 \\
\hline
\end{tabular}

مستعدتر از بقية بيماران هستند جون اغلب به مدت طولانى

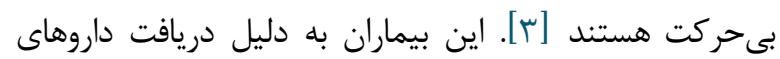

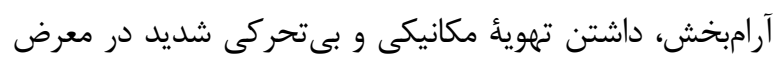

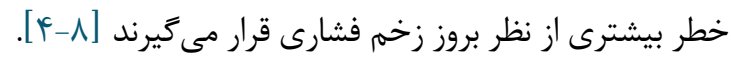

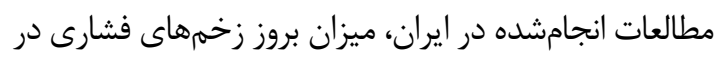
در بين بيماران بسترى در بخشهاى مراقبت ويزه را بيشتر از
زخم فشارى به عنوان نكروز قسمتى از يوست بدن تعريف

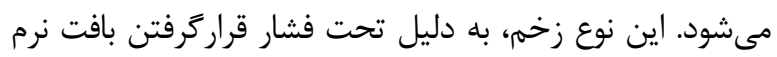
بدن بين يك قسمت برجسته استخوانى و يك سطح خارجى به

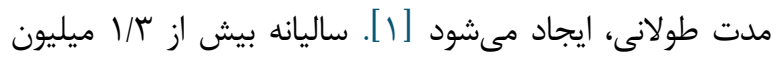
بزركسال در سراسر جهان به اين عارضه مبتلا مىشوند [ب]. اما بيماران بسترى در بخشهاى ويزه جهت ابتلا به زخم فشارى، 
اين روغنها و جربكنندهها، هيدراتهكردن يوست است. روغن

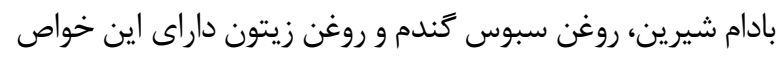

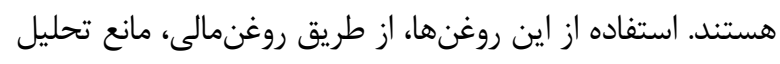

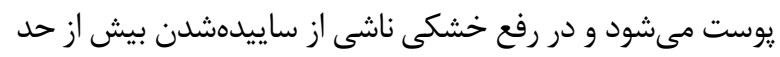

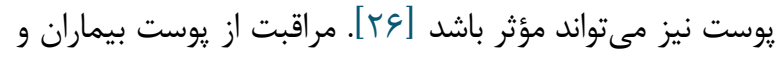

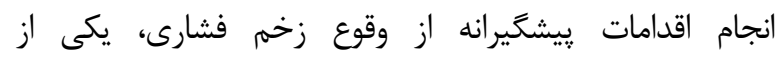

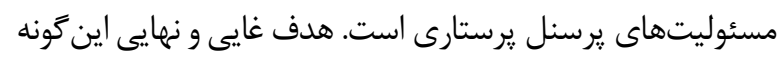

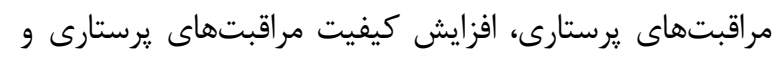

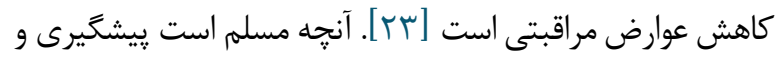
كنترل زخم فشارى، يكى از مصاديق كيفيت مراقبت نيز هست.

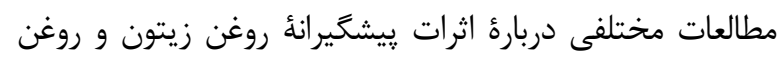
بادام شيرين در كنترل التهابهاى يوستى و بروز زخم فشارى نرئ

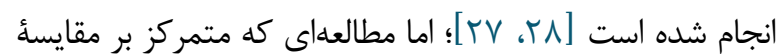

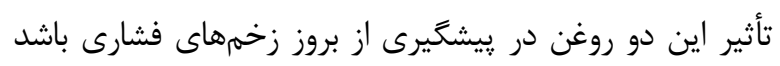

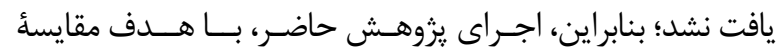

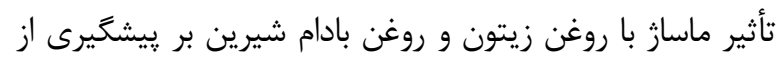

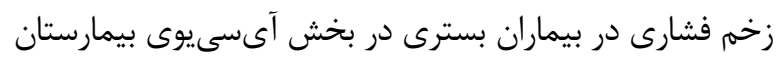

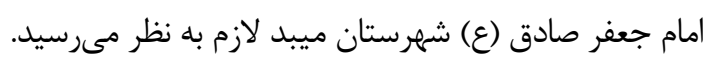

$$
\text { روش كار }
$$

اين يزوهش، مطالعهاى از نوع كار آزمايى بالينى تصادفىشده

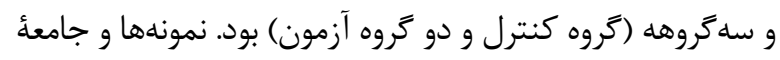

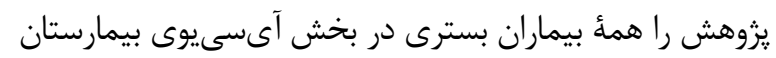

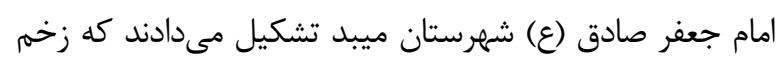

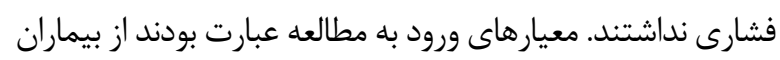

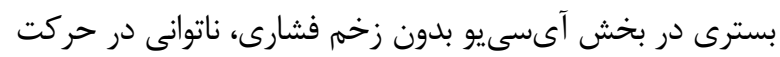
يا امكان حركت فقط به كمك وسايل كمك حركتى؛ معيارهاى

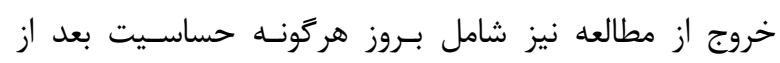

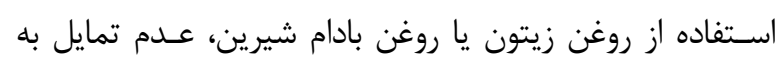

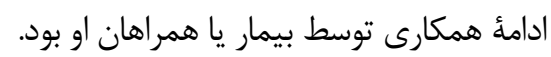

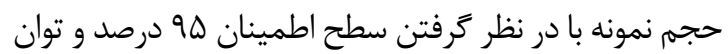

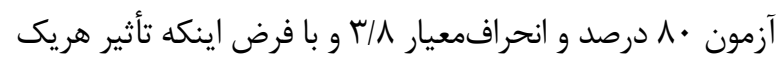

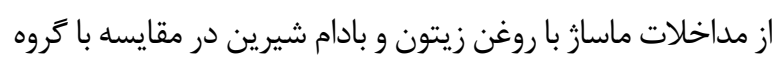

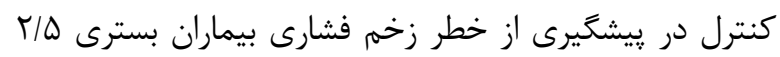

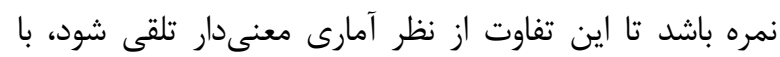

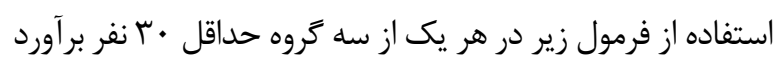

دورة
كشورهاى توسعه يافته كزارش كرداند [ [1-9]. شايعترين

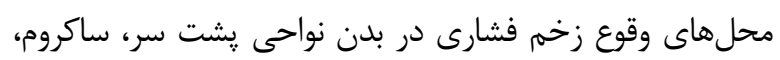

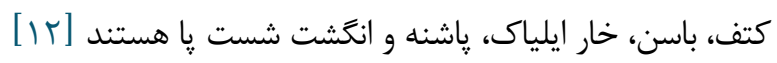

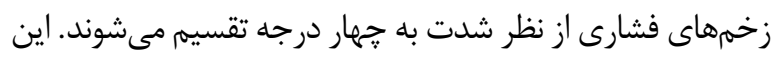

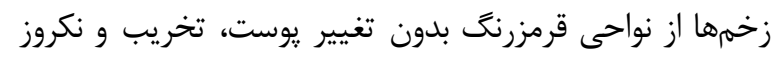

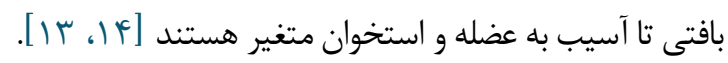

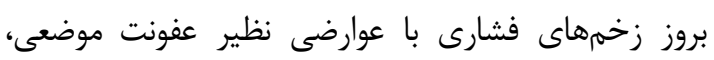

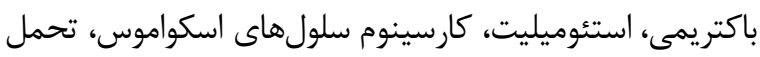

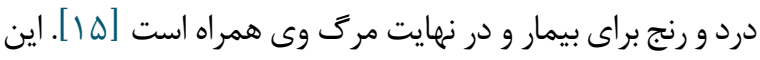

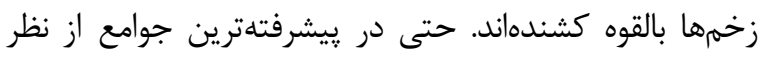

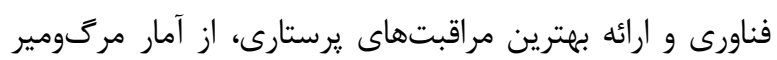

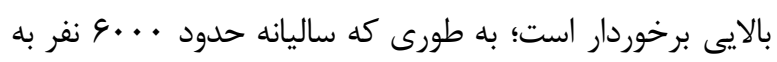

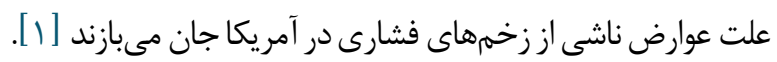

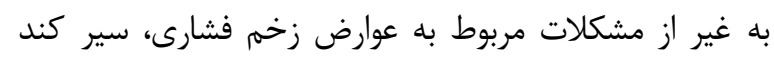

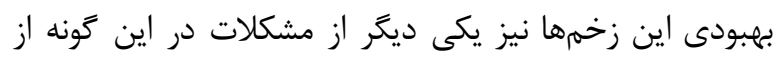

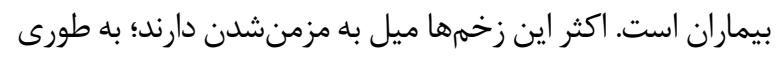

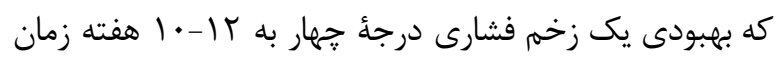

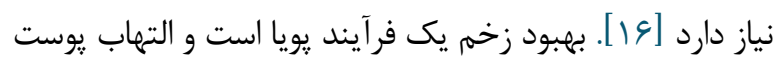

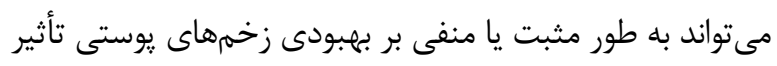

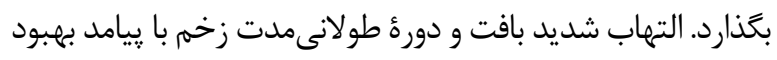

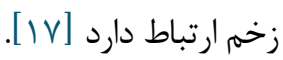
تأثير زخمهاى فشارى علاوه بر كاهش سطح سلامتى و ايجاد

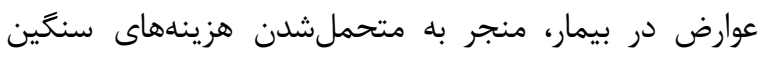

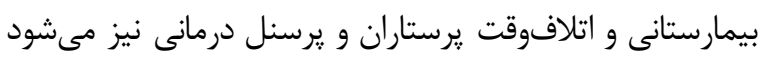

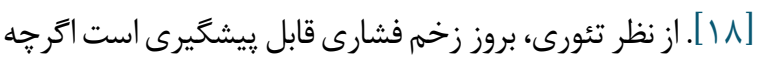

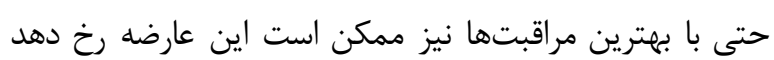

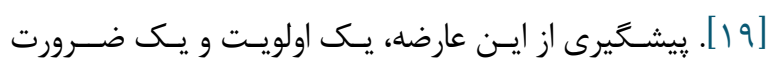

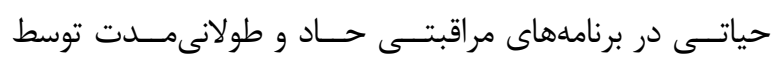

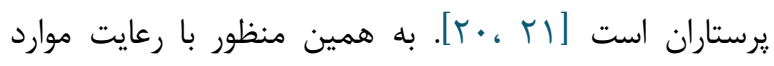

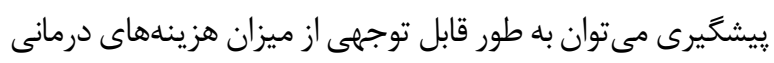

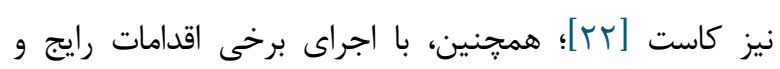

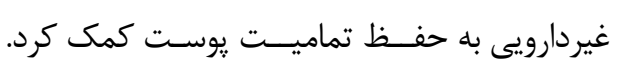

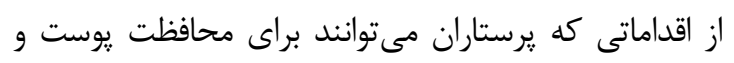

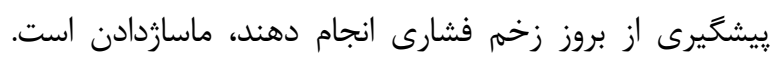

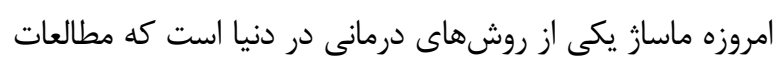

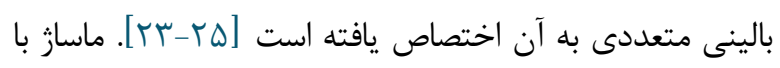

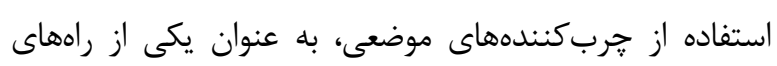

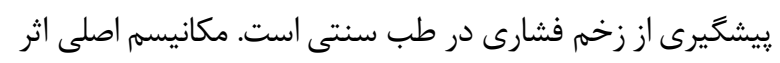

$$
\text { مجله مراقبت يرستارى و مامايى ابنسينا }
$$




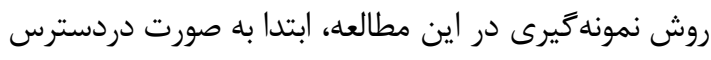
بود؛ سيس نمونهها به روش نمونهگيرى تصادفى و به روش روش بلوكهاى ششتايى كه بهوسيله نرمافزار انجام شد، به مطالعه وارد شدند. بدين صورت كه جايخشتهاى ششتايى در زروههاى سهَّانه قرار گرفتند؛ حرف A براى گروه كنترل، حرف B براى

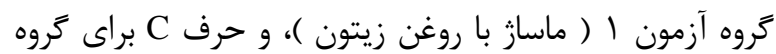

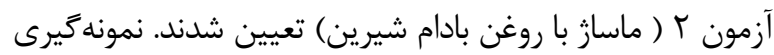

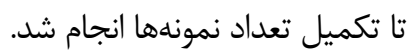
روش كار بدين صورت بود كه يكى از يزوهشگران يس از ارائهُ

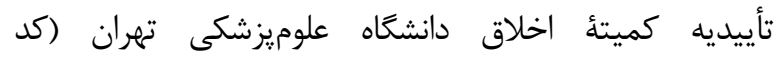
(IR.TUMS.FNM.REC.1396.2687 يزوهشى و جلب موافقت مسئولان بخش آىسىيوى بيمارستان امام جعفر صادق در روزهاى متوالى در اين بخش حضور يافت.

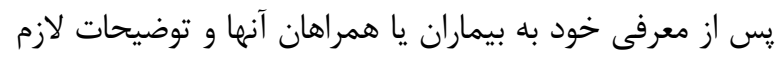

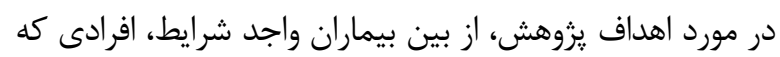
موافق شركت در مطالعه بودند ضمن اخذ رضايتنامه آكاهانئ كتبى به مطالعه وارد مىشدند. با در نظر گرفتن تفاوتهاى

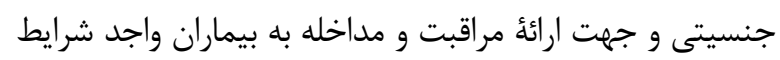
از همكار يزوهشخر استفاده شد. قبل از مداخله، ابتدا سلامت يوست بدن بيماران، در نواحى رهم

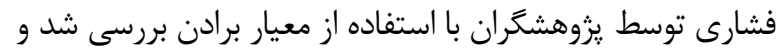

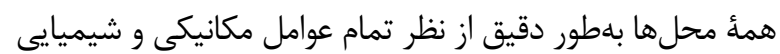
و باكتريال ايجادكننده زخم فشارى به طور دقيق مورد بررسى قرار زرفت. گروه كنترل فقط مراقبت روتين بخش، يعنى تغييـر

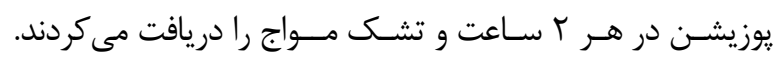

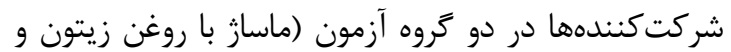
روغن بادام شيرين) علاوه بر درمان روتين (تغييـر يوزيشـن در

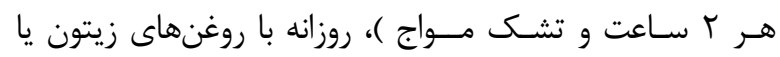

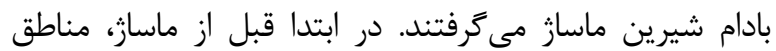
مستعد زخم فشارى از نظر بروز زخم فشارى بررسى مى مى مد و نيز

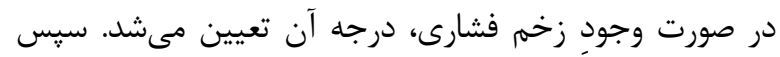
مناطق مستعد، تحت ماساز قرار مى گرفت. روش ماساز بدين صورت بود كه ابتدا ب-1 ميلىليتر روغن زيتون (در گروه آزمون

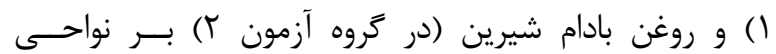

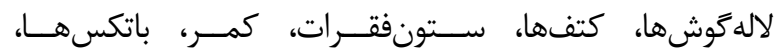

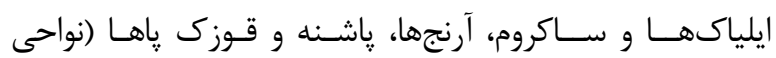

${ }^{3}$ Positive predictive value
شد. با در نظر ₹رفتن احتمال ريزش نمونه، در مجموع 91 نفر برآورد شد (فرمول شماره أ). فرمول شمارة أ

$$
\begin{gathered}
=\frac{\left(z_{1-\alpha / 2}+z_{1-\beta}\right)^{2}\left(\sigma_{1}^{2}+\sigma_{2}^{2}\right)}{\left(\mu_{1}-\mu_{2}\right)^{2}} n \\
z_{1-\alpha / 2}=1.96 \\
z_{1-\beta}=0.84 \\
\sigma_{1}=\sigma_{2}=3.8
\end{gathered}
$$

$\mathrm{d}=2 / 5$

ابزار گردآورى اطلاعات در اين يزوهش شامل يرسشنامه، مشخصات فردى و بيمارى، و جكليست مشاهدهأ محلهاى مستعد زخم از نظر بروز زخمم فشارى با استفاده از معيار برادن بود.

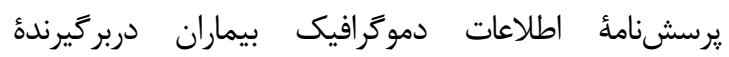
مشخصات فردى بيماران ازجمله سن، جنس، وضعيت تأهل، سطح تحصيلات، وضعيت اشتغال، وزن، قد، وشاخص توده بدنى ' (BMI) و ساير مشخصات مانند تشخيص بيمارى، نوع بيمارى، سطح هوشيارى بيمار با استفاده از مقياس كماى كلاسكو (GCS)، تاريخ مراجعه به بيمارستان، تاريخ بسترى در آىسىيو، مدت زمان

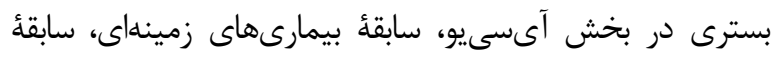

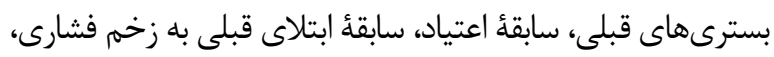

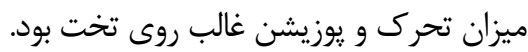

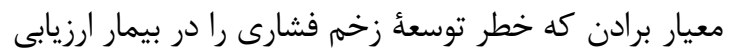
مى كند، داراى 4 معيار ارزيابى خطر در ابعاد اساسى ايجاد زخم

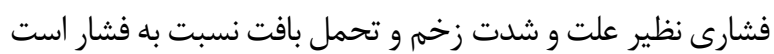

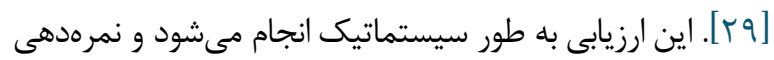

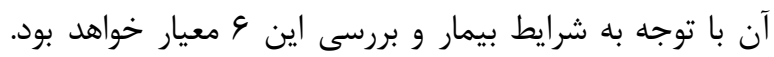

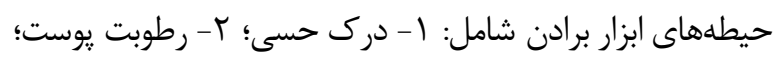
ץ- فعاليت؛ f - تحرك؛ ف- تغذيه؛ 9- اصطكاك و كشش هستند. هر حيطه در ابزار برادن از عدد ا (خيلى بد) تا أ (خوب) نمرهگذارى مىشود (بهجز قسمت نيروهاى اصطكاك و و

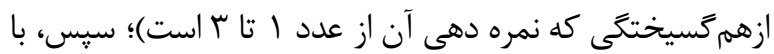
توجه به نمرهاى كه به بيمار داده مىشود خطر ايجاد زخم فشارى

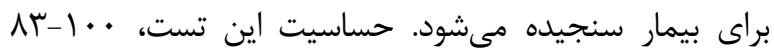
درصد و ويزگ

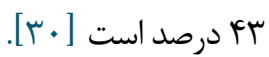

${ }^{1}$ Body Mass Index (BMI)

${ }^{2}$ Glascow Coma Scale (GCS) 
كروه به يك صورت بود و تفاوت معنى دارى بين سه كروه در طول زمان و در كل وجود نداشت (P>0/05). متغير رطوبت در طول زمان كاهش معنى ودار ندار داشته است

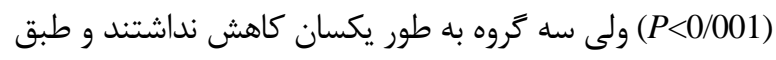

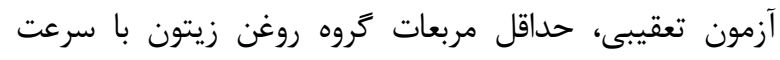

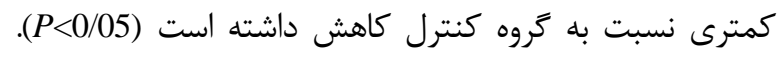

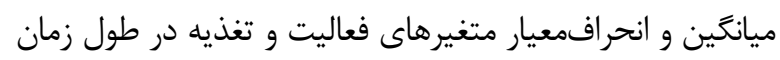

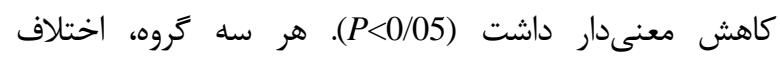

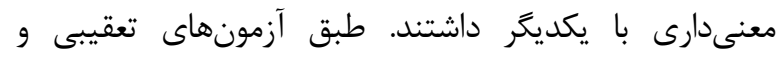

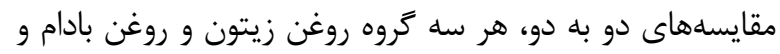

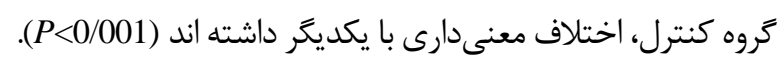

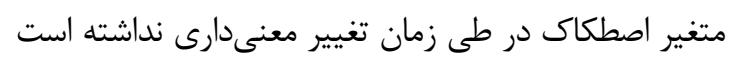

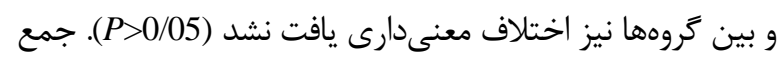

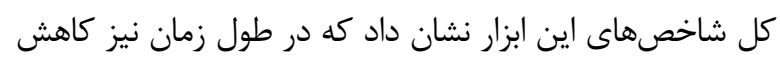

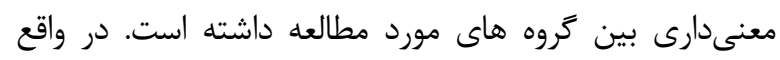

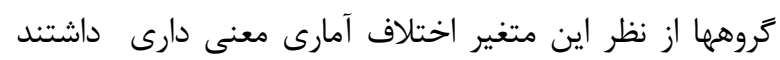

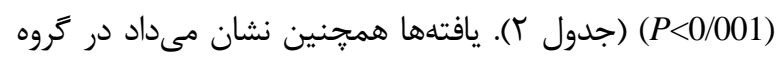

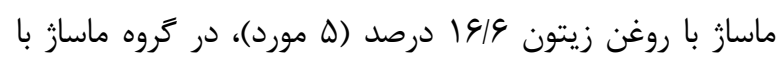

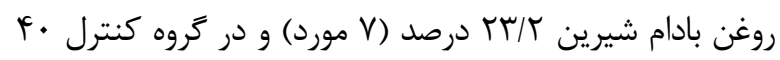

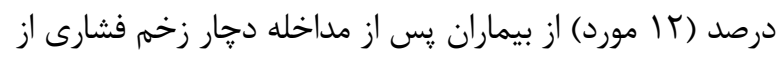

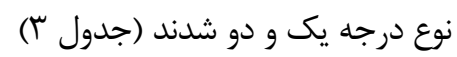
شايعترين محل بروز زخم فشارى در گروه ماساز با روغن

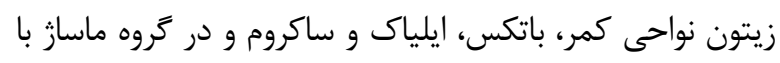

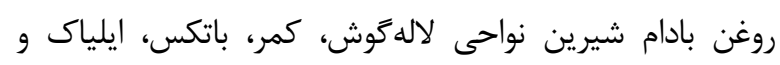

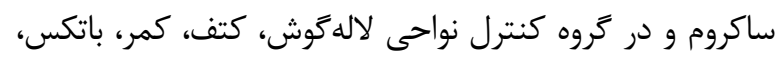
ايلياك و ساكروم بود.

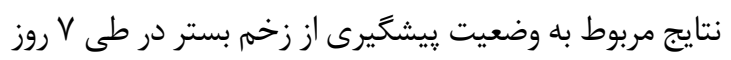

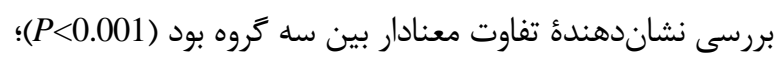

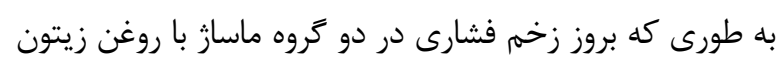

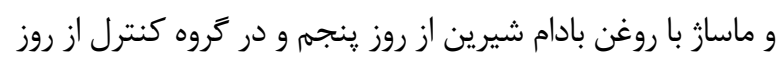

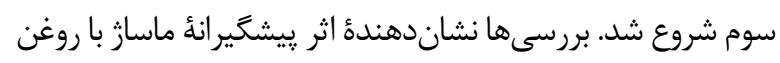

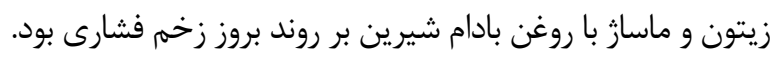

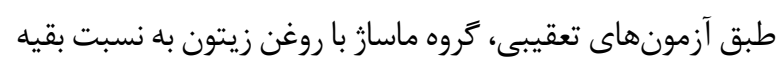

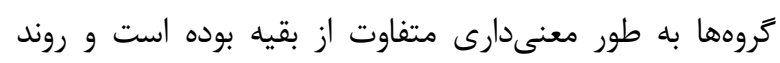
كندترى در كاهش بروز زخم فشارى داشته است (P>0/001)
فشارى) بهآرامى ماساز داده مىشد. اين مداخله روزانه، به مدت

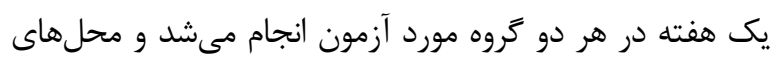

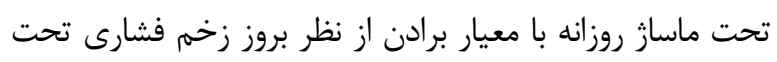

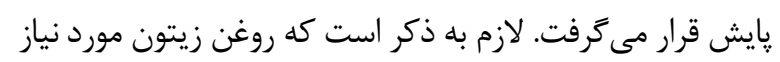

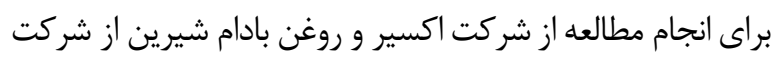

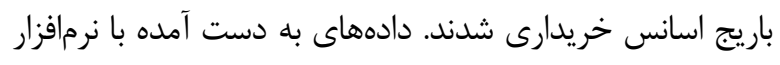

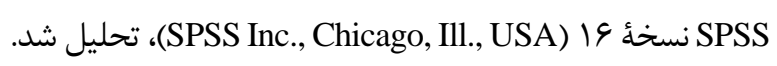
برحسب نوع دادهها، از آمار توصيفى و تحليلى نظير جداول توزيع آندائ

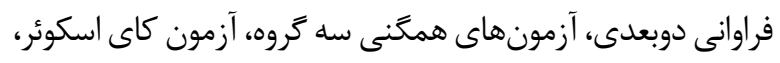

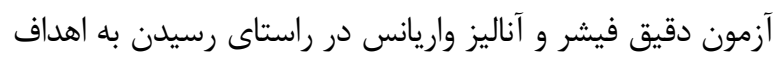

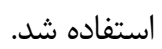

يافته ها

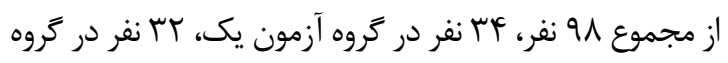

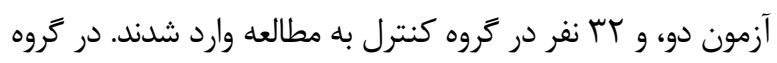

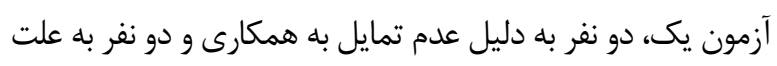

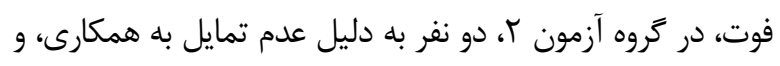

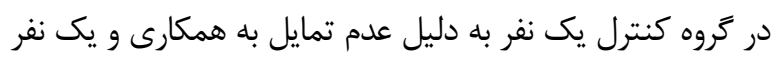

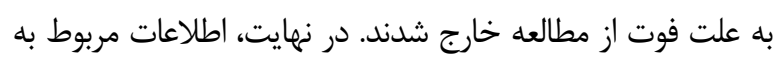

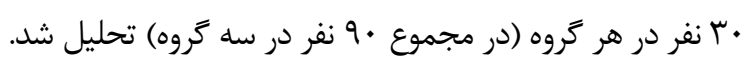

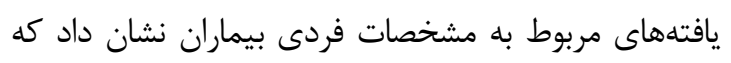

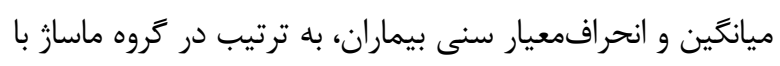

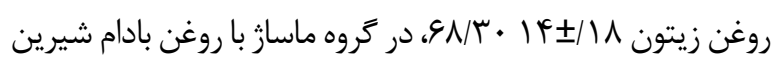

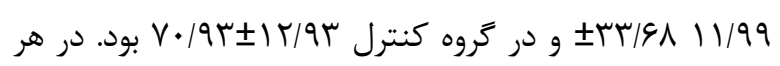
سه كروه بيشترين درصد شركت كنند

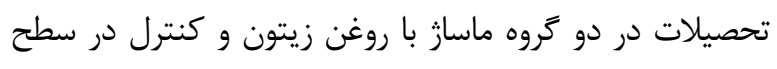

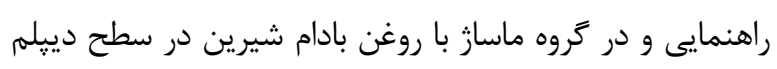

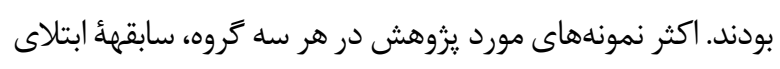

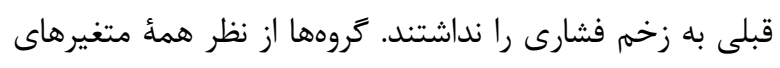

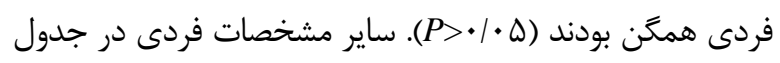
شماره ا كزارش شده است.

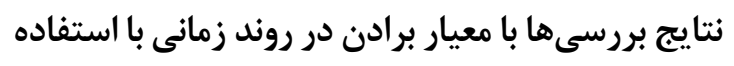
از آزمون اندازههاى تكرارى نشان مىداد ميانخين و انحرافمعيار

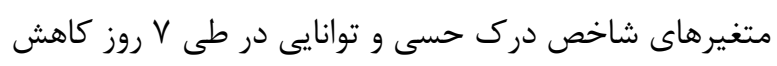

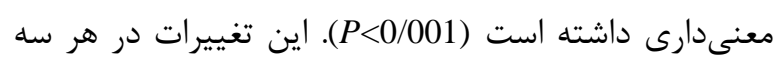


شكوه ورعى و همكاران roV

جدول 1. ميانَين و انحرافمعيار سن، BCS BMI و مدت زمان بسترى (روز) به تفكيك گروهها

\begin{tabular}{|c|c|c|c|c|}
\hline نتيجه تحليل واريانس & كروه كنترل & كروه آزمون r & كروه آزمون 1 & مشخصات \\
\hline$P=\cdot \mid 991$ & $V \cdot / 9 r \pm 1 r / 9 r$ & GN/TrE $11 / 99$ & $\varepsilon \Lambda / T \cdot \pm \mid F / / \Lambda$ & سن (سال) \\
\hline$P=1.99$ & $T Y / T V \pm T / V$. & $r r / r \varphi \pm r / q \Lambda$ & $r \Delta / \cdot \varphi \pm r / r \mid$ & BMI \\
\hline$P=\cdot \mid \Delta \varphi \varphi$ & $1 \cdot / r q \pm T / V \varepsilon$ & $9 / 8 \cdot \pm r / 9 \vee$ & $1 \cdot / r \Psi \pm T / V \Lambda$ & GCS \\
\hline מسז/א=•P & $q / r \varepsilon \pm 1 / \wedge \Delta$ & $1 \cdot / r \pm \pm r / 1 r$ & $|Y / \cdot r \pm r r /| \Lambda$ & مدت زمان بسترى (روز) \\
\hline
\end{tabular}

جدول r. مقايسُٔ سه كروه (ماساز با روغن زيتون و روغن بادام شيرين و كنترل) با معيار برادن در روند زمانى با استفاده از آزمون اندازههاى تكرارى

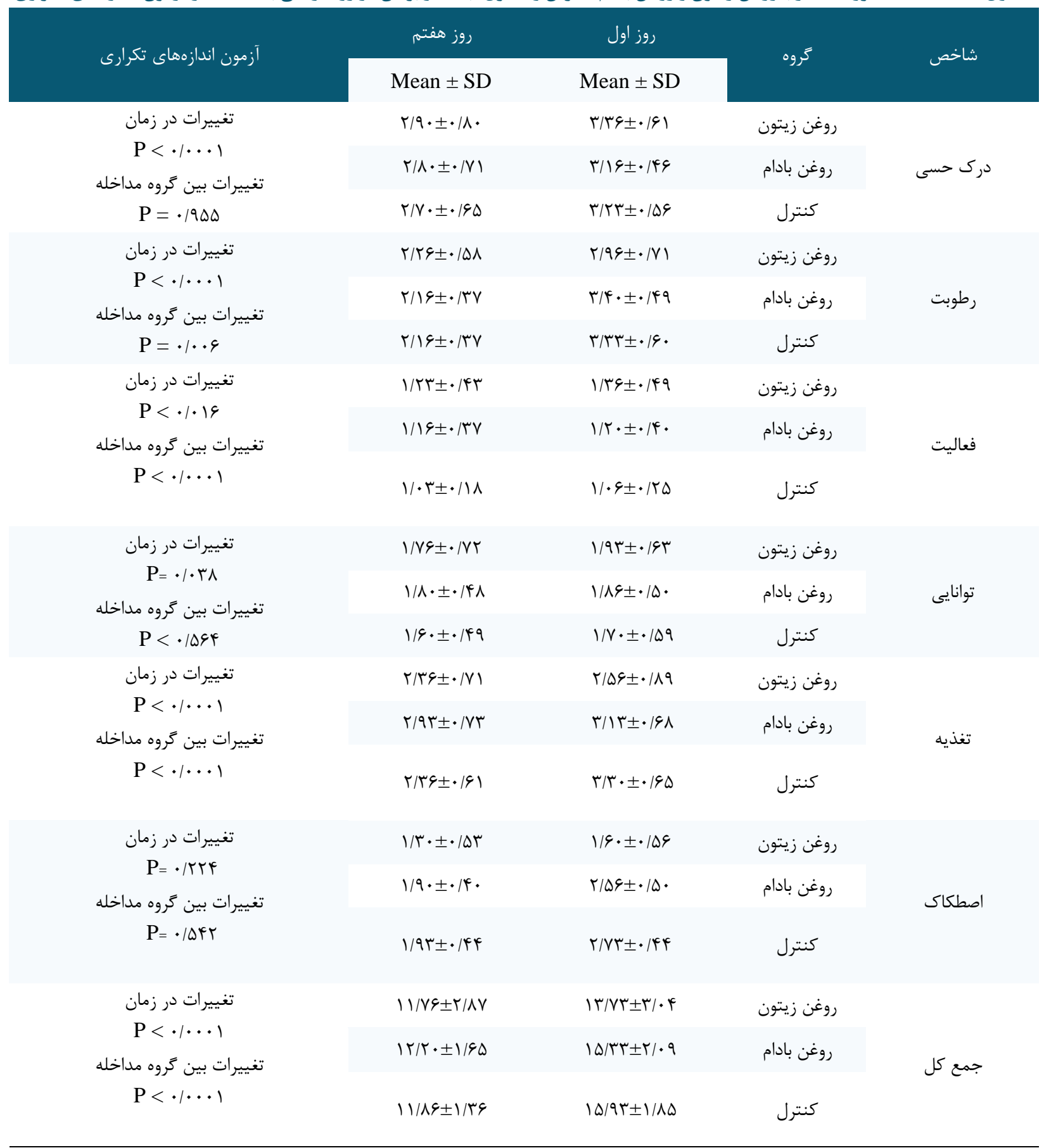


Aه مقايسٔ تأثير ماساز با روغن زيتون و روغن بادام شيرين در ييشخيرى از زخم فشارى

جدول با. مقايسُٔ فراوانى مطلق و نسبى درجهُ زخم فشارى ايجادشده در واحدهاى مورد مطالعه

\begin{tabular}{|c|c|c|c|c|c|c|}
\hline \multicolumn{2}{|c|}{ جمع - ا } & \multicolumn{2}{|c|}{ زخم فشارى درجه r } & \multicolumn{2}{|c|}{ زخم فشارى درجه 1} & درجات زخم فشارى \\
\hline در صد & فراوانى & در صد & 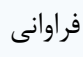 & در صد & فراوانى & كروه ها \\
\hline $19 / 9$ & $\Delta$ & r & 1 & 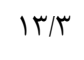 & f & كروه ماساز با روغن زيتون \\
\hline$r \mu / r$ & $V$ & $9 / 9$ & r & $19 / 9$ & $\Delta$ & شروه ماساز با روغن بادام \\
\hline$f$. & it & $\mid r / 4$ & r & T\&/G & $\wedge$ & كروه كنترل \\
\hline
\end{tabular}

بحث

و همكاران نيز در مطالعه خود كه به بررسى روغن بادام شيرين بر

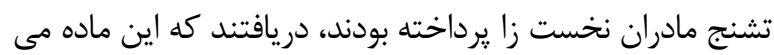

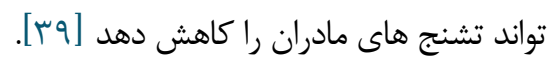

\section{نتيجة نهابي}

نتايج حاصل از اين مطالعه بيانخر آن بود كه ماساز با روغن

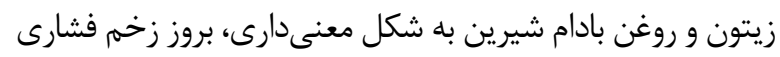

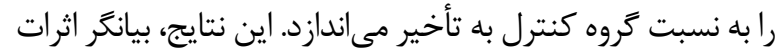
ييشخيرانه از زخم فشارى از طريق ماساز با اين روغنها است

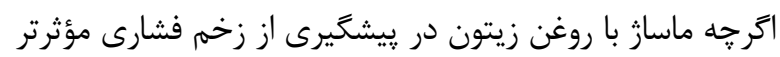

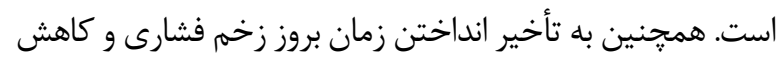
تعداد بيماران مبتلا به زخم فشارى از ديخر ريامدهاى مؤثر ماساز با اين روغنها است كه مىتواند اثرات صرفهجويى اقتصادى، افزايش گردش تختها در و يذيرش بيماران و افزايش كيفيت مراقبت يرستارى را با اين رويكرد مراقبت، ييش گيشيرانه ديد. از

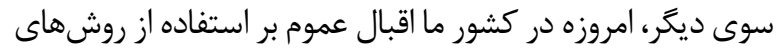
سنتى درمان وجود دارد. بنابر اين بيشنهاد مىشود ماساز با روغن

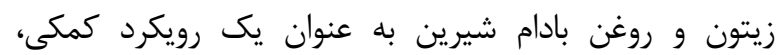
غيردارويى، كمهزينه و بدون عوارض جانبى، به منظور ييشگيرى

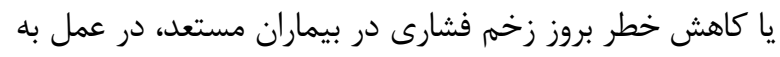

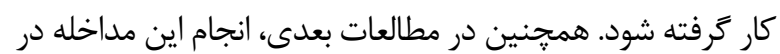
بازه زمانى بيش از يك هفته به اجرا عذاشته شود.

\section{سياسگزارى}

اين مقاله حاصل پاياننامٔه مقطع كارشناسى ارشد است

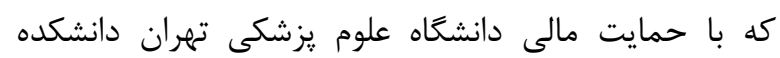

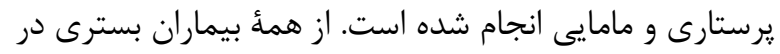

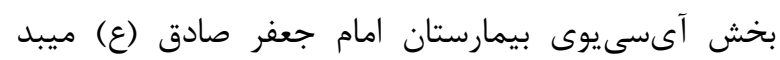

يزوهش حاضر نشان داد كه ماساز با روغن زيتون و بادام شيرين در بيشخيرى از بروز زخم فشارى مؤثر هستند. اثرات

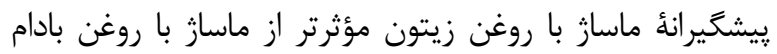
شيرين بود. نتايج مطالعات مختلف نيز نشان مى دهد كه استفاده موضعى از روغن زيتون در بيشخيرى از زخم فشارى بيماران مؤثر

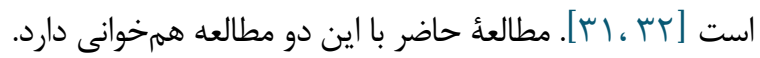
دربارة اثرات روغن زيتون و روغن بادام شيرين، مطالعاتى انجام شده كه بيانكر آن است، كه مصرف موضعى اين دو روغن روى رئ رئ يوست تأثيرات مثبتى دارد. زكرياى رازى، روغن زيتون خوراكى را براى درمان سردرد، درد مفاصل، زخم مقعد و ورم رودهها مفيد

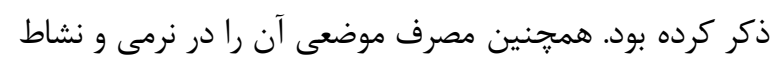
يوست، يِيشگيرى از تعريق و پيرى زودرس، درمان سبوره سر و

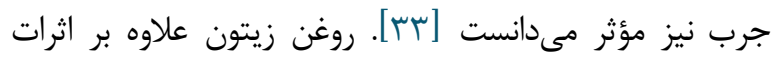
نرمكنند

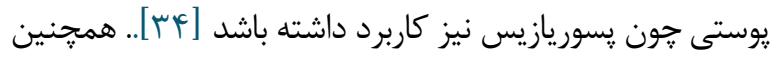

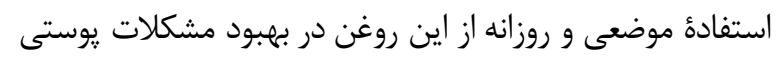
نوزادان نارس نيز مؤثر گزارش شده؛ به طورى كه مى تواند خط

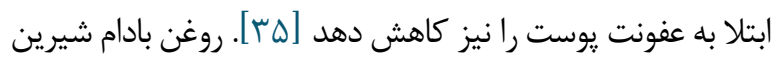
با دارا بودن لماه درصد روغن، منبعى غنى از ويتامين ميلى

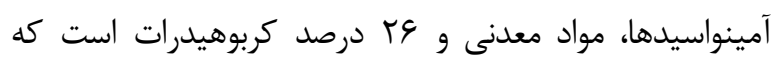
مىتوان از آن بهعنوان روغن در ماساز يوست استفاده كرد [عب].

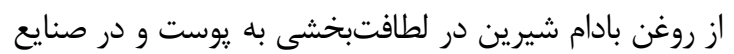

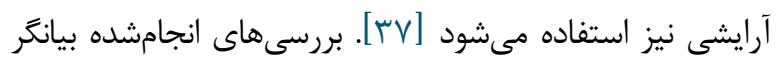

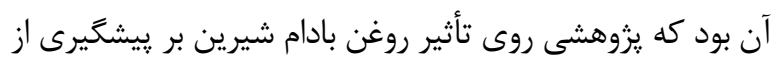
زخم فشارى انجام نشده است اما نتايج مطالعهُ Behnia و

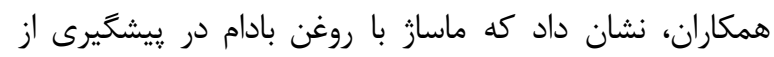

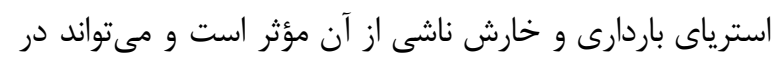

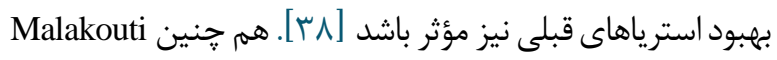




$$
\begin{aligned}
& \text { تعارض در منافع } \\
& \text { بين نويسند كان هيجگَنه تعارضى در منافع وجود ندارد } \\
& \text { منابع مالى } \\
& \text { منابع مالى اين مطالعه توسط نويسندكًان تامين شده است. }
\end{aligned}
$$

وابسته به دانشگاه علوميزشكى يزد و همكارانى كه ما را در اين يزوهش يارى كردند، تشكر و قدردانى مى كنيه. اين مطالعه

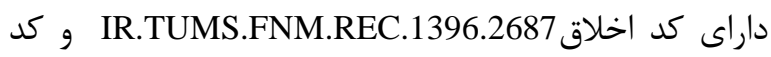

ثبت در مركز كارآمايى بالينى ايران با كد 20170124032147N4

\section{References}

1. Potter PA, Perry AG, Stockert P, Hall A. Fundamentals of Nursing, 9th ed. Canada: Mosby/Elsevier 2017.

2. Eugene F, Reilly Giorgos C, Karakousis, Sherwin P, Schrag SP, Stawicki. Pressure ulcer in the intensive care unit: the forgotten enemy. Opus 12 Scientist. 2007; $1(2): 17-30$.

3. Shahin ES, Dassen T, Halfens RJ. Pressure ulcer prevalence in intensive care patients: a cross-sectional study. Journal of Evaluation in Clinical Practice. 2008; 14(4):563-8. [DOI:10.1111/j.1365-2753.2007.00918.x] [PMID]

4. Keller BP, Wille J, van Ramshorst B, van der Werken C. Pressure ulcers in intensive care patients: a review of risks and prevention. Intensive Care Medicine. 2002; 28(10):1379-88. [DOI:10.1007/s00134-002-1487-z] [PMID]

5. Fernandes LM; Larcher Caliri MH, Vanderlei Haas J. The effect of educative intervention on the pressure ulcer prevention knowledge of nursing professionals. Acta Paulista de Enfermagem. 2008; 21(2):305-311. [DOI:10.1590/S0103-21002008000200012]

6. Elliott R, Mckinley S, Fox V. Quality improvement program to reduce the prevalence of pressure ulcers in an intensive care units. American Journal of Critical Care. 2008; 17(4):328-34.

7. Zarei E, Madarshahian E, Nikkhah A, Khodakarim S. Incidence of pressure ulcers in intensive care units and direct costs of treatment: Evidence from Iran. Journal of tissue viability. 2019 May 1;28(2):70-4. [DOI:10.1016/j.jtv.2019.02.001] [PMID]

8. Suriadi, Sanada H, Sugama J, Thigpen B, Kitagawa A, Kinosita S, Murayama S. A new instrument for predicting pressure risk in an intensive care unit. Tissue Viability Society. 2006; 16(3):21-6. [DOI:10.1016/S0965206X(06)63006-4]

9. Reihani H, Haghiri A. Determination of bed sore risk factors in craniospinal trauma patients in intensive care units. Journal of Arak University Medical Sciences. 2007; 10 (2) :39-46 URL: http://jams.arakmu.ac.ir/article-1-9en.html [In Persian]

10. AhmadiNejad M, Rafiei H. Pressure ulcer incidence in intensive care unit patients in Bahonar Hospital, Kerman. Journal of Iranian Society Anaesthesiology and Intensive Care. 2011; 57:10-6.

11. Bolorchi F, Abdolrahimi M. yaghmaee F, Akbarzadeh A. Incidence of pressure ulcer and risk factors in patient of orthopedic ward. Journal of Nursing and Midwifery. 2009; 19(67):1-5. [In Persian].
12. Morton PG, Fontaine DK. Critical care a holistic approach. 9th ed. Philadelphia: Lippincott Williams Wilkins; 2009.

13. Reddy M. Pressure ulcers. BMJ Clinical Evidence. 2011; 5:1901.

14. Terekeci H, Kucukardali Y, Top C, Onem Y, Celik S, Öktenli C. Risk assessment study of the pressure ulcers in intensive care unit patients. European Journal of Internal Medicine. 2009; 20(4):394-7. [DOI:10.1016/j.ejim.2008.11.001] [PMID]

15. Black JM, Hawks JH, Keene AM. Medical-surgical nursing: Clinical management for positive outcomes. Philadelphia: W.B. Saunders; 2001.

16. Shahin ES, Dassen T, Halfens RJ. Incidence and prevention and treatment of pressure ulcers in intensive care patients: A longitudinal study. International Journal of Nursing Studies. 2009; 46(4):413-21. [DOI:10.1016/j.ijnurstu.2008.02.011] [PMID]

17. Reinke JM, Sorg H. Wound repair and regeneration. European Surgical Research. 2012; 49(1):35-43. [DOI:10.1159/000339613] [PMID]

18. Collins F. Vicair Academy mattress in the prevention of pressure damage. Br J Nurs. 2002; 11(10):715-8. doi: 10.12968/bjon.2002.11.10.715 [DOI:10.12968/bjon.2002.11.10.715] [PMID]

19. Massey PM. Resolution of early stage pressure sores after treatment with specific skin cream. Chicago: Curapharm Inc; 2007.

20. Beigi Boroujeni V, Beigi AA, Avijgan M, Beigi Boroujeni N, Rohei Borojeni H, Daris F. The effects of Aleo vera gel on chronic ulcers in comparison with current treatment. Journal of Lorestan University of Medical Sciences. 2009; 11(1):15-22. [In Persian]

21. Kottner J, Lahmann N, Dassen T. pressure ulcer prevalence: comparison between nursing homes and hospitals. Pflege Z. 2010; 63(4):228-31.

22. Stephens F, Bick D. Risk assessment and prevention audit project. Nurs Stand. 2002; 16(44):62-4 https://doi.org/10.7748/ns2002.07.16.44.62.c3233 [DOI:10.7748/ns.16.44.62.s17] [PMID]

23. Young ZF, Evans A, Davis J. Nosocomial pressure ulcer prevention: A successful project. The Journal of Nursing Administration. 2003; 33(7-8):380-3. [DOI:10.1097/00005110-200307000-00004] [PMID]

24. Andrade CK. Outcome-Based massage from evidence to practice. 3rd ed. Philadelphia: Lippincott Williams and Wilkins; 2013. 


$$
\text { • ع مقايسُٔ تأثير ماساز با روغن زيتون و روغن بادام شيرين در ييشخيرى از زخم فشارى }
$$

25. Ezzo J, Haraldsson BG, Gross AR, Myers CD, Morien A, Goldsmith $\mathrm{CH}$, et al. Massage for disorders: a systematic review. Spine. 2007; 32(3):353-62. [DOI:10.1097/01.brs.0000254099.07294.21] [PMID]

26. . Hosseinzadeh H, Nassiri-Asl M. Avicenna's (Ibn Sina) the Canon of Medicine and saffron (Crocus sativus): a review. Phytotherapy Research. 2013 Apr;27(4):475-83. [DOI:10.1002/ptr.4784] [PMID]

27. 27. Behnammoghadam M, Paymard A, Salehian T, Shahnavazi A, Bakhshi F, Allahyari E, et al. Effect of topical olive oil on prevention of bed sore in patients admitted to ICU in Yasuj Shahid Beheshti Hospital: A double-blind randomized clinical trial. Journal of Anesthesiology and Pain. 2017; 7(4):54-61.

28. Abbas Ali Madadi Z, Zeighami R, Azimian J, Javadi A. The effect of topical olive oil on prevention of bedsore in intensive care units patients. International Journal of Research in Medical Sciences. 2015; 3(9):2342-7. [DOI:10.18203/2320-6012.ijrms20150628]

29. Lindgren M, Unosson M, Krantz AM, Ek AC. A risk assessment scale for the prediction of pressure sore development: reliability and validity. Journal of Advanced Nursing.2002; 38(2):190-9. [DOI:10.1046/j.1365-2648.2002.02163.x] [PMID]

30. Lyder $\mathrm{CH}$. Assessing risk and preventing pressure ulcers in patients with cancer. . 2006; 22(3):178-84. [DOI:10.1016/j.sonen.2006.04.002] [PMID]

31. Donato-Trancoso A, Monte-Alto-Costa A, RomanaSouza B. Olive oil-induced reduction of oxidative damage and inflammation promotes wound healing of pressure ulcers in mice. Journal of dermatological science. 2016 Jul 1;83(1):60-9. [DOI:10.1016/i.jdermsci.2016.03.012] [PMID]

32. Lupiáñez-Pérez I, Morilla-Herrera JC, Ginel-Mendoza L, Martín-Santos FJ, Navarro-Moya FJ, Sepúlveda-Guerra RP, Vázquez-Cerdeiros R, Cuevas-Fernández-Gallego M, Benítez-Serrano IM, Lupiáñez-Pérez Y, MoralesAsencio JM. Effectiveness of olive oil for the prevention of pressure ulcers caused in immobilized patients within the scope of primary health care: study protocol for a randomized controlled trial. Trials. 2013 Dec;14(1):348. [DOI:10.1186/1745-6215-14-348] [PMID] [PMCID]

33. Casas R, Estruch R, Sacanella E. The protective effects of extra virgin olive oil on immune-mediated inflammatory responses. Endocrine, Metabolic \& Immune DisordersDrug Targets (Formerly Current Drug Targets-Immune, Endocrine \& Metabolic Disorders). 2018 Jan 1;18(1):2335. [DOI:10.2174/1871530317666171114115632] [PMID]

34. Souza PA, Marcadenti A, Portal VL. Effects of olive oil phenolic compounds on inflammation in the prevention and treatment of coronary artery disease. Nutrients. 2017 Oct;9(10):1087. [DOI:10.3390/nu9101087] [PMID] [PMCID]

35. Taavoni S, Soltanipour F, Haghani H, Ansarian H, Kheirkhah M. Effects of olive oil on striae gravidarum in the second trimester of pregnancy. Complement Ther Clin Pract. 2011; 17(3):167-9. [DOI:10.1016/j.ctcp.2010.10.003] [PMID]
36. Soler L, Canellas J, Saura-Calixto F. Oil content and fatty acid composition of developing almond seed. J. Agric. Food Chem. 1988; 36(4):695-7. [DOI:10.1021/if00082a007]

37. Lin TK, Zhong L, Santiago JL. Anti-inflammatory and skin barrier repair effects of topical application of some plant oils. I nt J Mol Sci. 2017; 19(1):e70. [DOI:10.3390/ijms 19010070] [PMID] [PMCID]

38. Behnia H, Hosseini M. The protective effect of almond oil and glycerin in striae gravidarum. Pejouhandeh. 2000; 5(3):317-20. [In Persian]

39. Malakouti J, Farshbaf Khalili A, Kamrani A. Sesame, sweet almond \& sesame and sweet almond oil for the prevention of striae in primiparous females: a triple-blind randomized controlled trial. Iranian Red Crescent Medical Journal. 2017; 19(6):e33672. [DOI:10.5812/ircmj.33672]
دورة
مجله مراقبت برستارى و مامايى ابنسينا 